\title{
Effect of severe sepsis on platelet count and their indices
}

\author{
*Guclu E, Durmaz Y, Karabay O
}

Department of Infectious Diseases and Clinical Microbiology, Ministry of Health Sakarya University Training and Research Hospital, Sakarya, Turkey

\begin{abstract}
Background: Sepsis is a major disease affecting almost all organs and systems.

Objectives: To examine platelet count and indices (mean platelet volume (MPV) and platelet distribution width (PDW)) in severe sepsis.

Methods: Patients with criteria for sepsis at a first examination by an Infectious Diseases specialist were selected. Consecutive patients who were admitted to the out-patient clinic and who were not diagnosed with any infectious disease were selected as the control group.

Results: A total of 145 patients with sepsis and 143 patients as a control group were included in the study. MPV and PDW were significantly differentbetween sepsis patients and control group $(\mathrm{P}<0.05)$. Platelet count in sepsis patients was lower than control group but the difference was not significant. PDW was the unique significantly different parameter between survivors and non-survivors $(\mathrm{p}=0.001)$.

Conclusions: Platelet indices are important laboratory findings in the diagnosis of sepsis and severe sepsis. Severe sepsis patients who have greater than $18 \%$ PDW levels have a higher risk of death. Therefore, PDW, which is part of an inexpensive, easily accessible and routinely performed test for almost all patients admitted to health facilities may be used for predicting mortality.
\end{abstract}

Key words: Severe sepsis, thrombocyte, thrombocytopenia, Mean Platelet Volume, Platelet distribution width African Health Sciences 2013; 13(2): 333 - 338 http://dx.doi.org/10.4314/ahs.v13i2.19

\section{Introduction}

Sepsis is a major disease affecting millions of people worldwide each year. ${ }^{1}$ Approximately 750,000 cases of sepsis per year were seen in the United States (US), and led to 215,000 death. The economic burden of this disease for the US was 16.7 billion US dollars/ year ${ }^{2}$. Almost all organs and systems are affected by sepsis. The haemostatic system is also adversely affected. ${ }^{3}$ In sepsis pathophysiology: clotting cascades do not function, many pro- and anti-inflammatory cytokines are released from mononuclear and endothelial cells, thrombus occurs in later stages, and plasminogen stimulation and antithrombin-III activation take place in the fibrinolytic system. ${ }^{4}$ As a result, fibrinolytic and fibrinogen substances are depleted, and formation of clots and bleeding associated with disseminated intravascular coagulation (DIC) occur at the same time. In the end, DIC results with increased platelet destruction. ${ }^{5,6}$

*Corresponding author:
Dr. Ertugrul Guclu
Ministry of Health
Sakarya University Training and Research Hospital
Sakarya, Turkey
Phone: (090) 2642751010
E-mail: ertugrulguclu@hotmail.com

African Health Sciences Vol 13 Issue 2 June 2013
There is also peripheral non-immune destruction, hemophagocytic histiocytosis, and marrow suppression, all playing different roles in thrombocytopenia in septic patients. ${ }^{7}$

The contribution of thrombocytopenia in severe sepsis has not been clearly established., The normal range of platelet counts in adults is 150,000 $-400,000 / \mu \mathrm{L}$. Higher platelet counts are observed in females than in males ${ }^{8}$. Approximately $40 \%$ of patients with severe sepsis have platelet counts less than $80,000 / \mathrm{mm}^{3} .^{7}$ Decreased platelet counts parallel the severity of infection. ${ }^{9}$

Mean platelet volume (MPV) is a measurement of the average size of platelets found in the blood. There are high MPV levels in destructive thrombocytopenia and low MPV levels in hypoproliferative thrombocytopenia ${ }^{10,11}$. Platelet distribution width (PDW) is an indicator of variation in platelet size. Normal values of PDW are between $10 \%$ and 17.9 $\%{ }^{12}$

Easily accessible, inexpensive, and widely used laboratory tests that show the severity of sepsis are important. MPV and PDW are widely and routinely used in clinical practice worldwide. Higher MPV and increased PDW have been found in sepsis. ${ }^{3}$ However, the role of these parameters in severe sepsis have not been investigated. 
In this study, we aimed to investigate the relationship between severe sepsis and platelet count, MPV, and PDW.

\section{Methods}

\section{Study design and Setting}

This is a retrospective cohort study that was conducted between September 2011 and May 2012 in a tertiary training and research hospital. Our hospital consists of two campuses $(400+200$ bed capacity) with a total of 220 doctors, 315 nurses and 180 auxiliary health personnel. There are two general intensive care units (ICUs) with 10 and five beds, one cardiac ICU with six beds, and one neurological ICU with six beds in our hospital. The infection control team consists of one Infectious Diseases and Clinical Microbiology (IDCM) clinical director, four IDCM specialists and two infection control nurses. IDCM specialists and infection control nurses evaluate the patients in ICU every day and prescribe their antibiotics.

\section{Study group}

Patient medical records and the electronic patient data monitoring system were examined retrospectively. Patients diagnosed as sepsis, severe sepsis, and septic shock at the first medical examination by an IDCM specialist were included.

\section{Control Group}

Control group/patients were selected from consecutive patients who were admitted to the outpatient clinic.

Selection criteria for the control group were:

- no infectious disease diagnosis,

- normal C-reactive protein (CRP) level in laboratory examination

- normal leukocyte count in laboratory examination - no systemic inflammatory response syndrome (SIRS) criteria in his/her medical records

\section{Definitions}

The diagnosis of sepsis was made during the first examination. Sepsis was defined as SIRS with a proven or suspected source of infection. SIRS was defined as two or more of the perturbations in table 17. Patients who had organ dysfunction and/or hypoperfusion abnormalities were defined as severe sepsis (table 1). ${ }^{1}$ Thrombocytopenia was defined as a platelet count lower than $150,000 / \mathrm{mm}^{3}$.

Table 1: Criteria of systemic inflammatory response syndrome and severe sepsis

\begin{tabular}{ll}
\hline Systemic inflammatory response syndrome criteria ${ }^{7}$ & Severe sepsis criteria $^{1}$ \\
\hline $\begin{array}{l}\text { 1. Temperature }\left(>38^{\circ} \mathrm{C} \text { or }<36^{\circ} \mathrm{C}\right) \\
\text { 2. Heart rate }(>90 \text { beats } / \text { minute })\end{array}$ & $\begin{array}{l}\text { 1. Arterial hypoxemia }(\mathrm{PaO} 2 / \mathrm{FiO} 2<300) \\
\text { least } 2 \text { hours) }\end{array}$ \\
$\begin{array}{ll}\text { 3. Respiratory rate }>20 \text { breaths } / \mathrm{minute} \text { or } \mathrm{PaCo}_{2}<32 \mathrm{mmHg} & \text { 3. Creatinine (increase }>0.5 \mathrm{mg} / \mathrm{dL}) \\
\text { 4. White blood cell count }>12.000 \text { cells } / \mathrm{mm}^{3} \text { or }<4000 \text { cells } / & \text { 4. Coagulopathy (INR }>1.5 \mathrm{or} \mathrm{PTT}>60 \mathrm{sec}) \\
\mathrm{mm}^{3} \text { or }>10 \% \text { immature band forms } & \text { 5. Ileus } \\
& \left.\text { 6. Thrombocytopenia (platelet count }<100,000 \mathrm{~mm}^{3}\right) \\
& \text { 7. Hyperbilirubinemia (bilirubin }>4 \mathrm{mg} / \mathrm{dL})\end{array}$ \\
\hline
\end{tabular}

\section{Demographic characteristics}

Demographic characteristics, such as age, gender, and the reason for hospitalization (medical or surgical) and laboratory results (whole blood count and CRP) at admission were obtained from patient files. Also, patient files were investigated for 28-day mortality. Patients who were discharged within 28 days after diagnosis of sepsis and who continued to have follow-up in the hospital at the $28^{\text {th }}$ day of patient monitoring were accepted as survivors. Patients who died within the 28 days of patient monitoring were accepted as non-survivors.

\section{Statistical methods}

The Kolmogorov-Smirnov test was used to evaluate whether the distribution of variables were normal. Two independent sample $t$ test was used to compare the normal distributed continuous variables between groups. Normal distributed continuous variables were presented as mean \pm standard deviation. MannWhitney $\mathrm{U}$ test was used to compare the non-normal distributed continuous variables between groups. Non-normal distributed continuous variables were presented as the median and interquartile range (IQR, quartile 1 to 3). Categorical variables were compared by Pearson's or Yates corrected Chi-Square tests. Categorical variables were presented as a count and percentage. 
Receiver operating characteristic (ROC) curve analysis was performed to establish the most accurate diagnostic method (biomarker) to discriminate between sepsis and normal. ROC curves were constructed for Platelet, mean platelet volume and platelet distribution Width to test the various biomarkers in predicting sepsis (figure1). The areas under the ROC curves (AUC) were calculated and the specificity, sensitivity, positive-predictive value (PPV), negative-predictive value (NPV), and accuracy, for the platelet, mean platelet volume and platelet distribution Width of the most appropriate cut-off point were calculated for predicting sepsis. A multivariate logistic regression model was implemented to determine Platelet, Mean Platelet volume and Platelet distribution Width and other covariates associated with sepsis. A p-value $<0.05$ was considered significant. Analyses were performed using commercial software (IBM SPSS Statistics 20, SPSS inc., IBM Co., Somers, NY; MedCalc11, Mariakerke, Belgium).

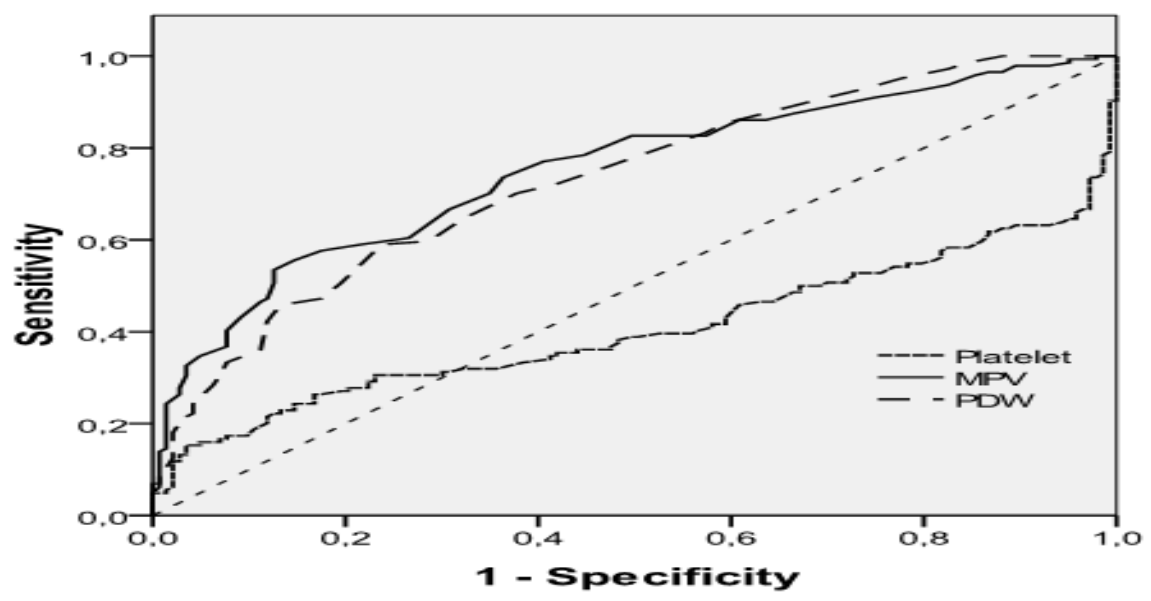

Figure 1: Receiver operating characteristic (ROC) curves for measurements of Platelet, Mean Platelet Volume, and Platelet Distribution Width to detect sepsis

\section{Results}

A total of 145 sepsis patients were included in this study. The study population consisted of 61 females and 84 males, of which 22 were surgical and 123 medical patients. Also, 143 patients (49 females and 94 males) were included as a control group.

Thrombocytopenia was observed in 49 (33.8\%) patients with sepsis and in $4(2.8 \%)$ patients in the control group $(\mathrm{p}<0.001)$. Age and gender were statistically similar between septic patients and the control group ( $\mathrm{p}>0.05)$. However, a statistically significant difference was found in MPV and PDW between patients with sepsis and the control group (table 2) $(\mathrm{p}<0.05)$.

Out of 145 sepsis patients, 88 (60.7\%) of them were diagnosed as having severe sepsis. Thrombocytopenia was observed in $36(40.9 \%)$ severe sepsis patients and in $13(22.8 \%)$ non-severe sepsis patients $(p=0.01)$. While a statistical difference was not found between sepsis and severe sepsis patients in terms of demographic characteristics, CRP, leukocyte, and neutrophil count, there was a meaningful statistical difference in platelet count and their indices as indicated in table 3.

Table 2: Demographic characteristics and laboratory findings of patients with sepsis and control groups

\begin{tabular}{lllc}
\hline Characteristics & $\begin{array}{l}\text { Patients with } \\
\text { sepsis(n=145 }\end{array}$ & $\begin{array}{l}\text { Control group } \\
(\mathbf{n}=\mathbf{1 4 3})\end{array}$ & $\boldsymbol{p}$ value \\
\hline Gender (Male) & $84(57.9)$ & $94(65.7)$ & 0.173 \\
Age (years) & $69,0[49.5-78,0]$ & $62,0[55,0-73,0]$ & 0.784 \\
Platelet (K/uL)5 & $228000 \pm 133000$ & $246000 \pm 67000$ & 0.148 \\
Mean Platelet Volume (fl)3 & $8.4 \pm 1.7$ & $7.1 \pm 1,0$ & $<\mathbf{0 . 0 0 1}$ \\
Platelet Distribution Width (\%)4 & $18,2[17,5-19,1]$ & $17,3[16,9-17,9]$ & $<\mathbf{0 . 0 0 1}$ \\
\hline
\end{tabular}

Data were shown as mean \pm standard deviation,median [IQR] and $\mathrm{n}(\%)$ 
Table 3: Demographic and laboratory findings of patients with sepsis and severe sepsis

\begin{tabular}{llll}
\hline Characteristics & $\begin{array}{l}\text { Patients with sepsis } \\
(\mathbf{N}=57)\end{array}$ & $\begin{array}{l}\text { Patients with severe sepsis } \\
(\mathbf{N}=\mathbf{8 8})\end{array}$ & $\boldsymbol{p}$ value \\
\hline Gender (Male) & $34(59.6)$ & $50(56.8)$ & 0.869 \\
Age (years) & $62.2 \pm 20.1$ & $63.1 \pm 17.6$ & 0.788 \\
C-Reactive Protein $(\mathrm{mg} / \mathrm{L})$ & $150,0[47,0-230,5]$ & $144[62,8-278,3]$ & 0.838 \\
Leukocyte (K/uL) & $13700 \pm 8050$ & $14200 \pm 8900$ & 0.742 \\
Neutrophil (K/uL) & $11650 \pm 7780$ & $12200 \pm 8410$ & 0.683 \\
Platelet (K/uL) & $264000 \pm 129100$ & $204500 \pm 130800$ & $\mathbf{0 . 0 0 8}$ \\
Mean Platelet Volume (fl) & $7,0[7,0-8,0]$ & $8,0[7,0-9,0]$ & $\mathbf{0 . 0 0 1}$ \\
Platelet Distribution Width (\%) & $17,0[17,0-18,5]$ & $18,0[17,0-19,0]$ & $\mathbf{0 . 0 3 0}$
\end{tabular}

Data were shown as mean \pm standard deviation, median $[\mathrm{IQR}]$ and $\mathrm{n}(\%)$.

Among the 145 sepsis patients, 51 (35.2\%) of them died within the 28-day follow-up. Thrombocytopenia was observed in $19(37.3 \%)$ of the non-survivors and in $30(31.9 \%)$ of the survivors $(\mathrm{p}=0.51)$. There was no statistical difference between survivors and non-survivors in terms of demographic characteristics and laboratory findings, except for PDW. PDW in non-survivors was significantly higher than in survivors $(p=0.001)$.
Demographic characteristics and laboratory findings of survivors and non-survivors are seen in table 4.

MPV levels higher than $8 \mathrm{fl}$ have $53.47 \%$ sensitivity and $87.41 \%$ specifity for sepsis diagnosis. The results of ROC curve analysis are shown in table 5. On multivariate analysis, the significant independent risk factors for sepsis were age, MPV, and PDW (table 6).

Table 4: Characteristics of sepsis patients who did or did not survive within the 28-day followup

\begin{tabular}{llll}
\hline Characteristics & Survivor(n=51) & $\begin{array}{l}\text { Non-survivor } \\
(\mathbf{n = 9 4 )}\end{array}$ & $\boldsymbol{p}$ value \\
\hline Gender (Male) & $29(56.9)$ & $55(58.5)$ & 0.84 \\
Age (years) & $66.5 \pm 18.5$ & $60.7 \pm 18.5$ & 0.073 \\
C-Reactive Protein (mg/L) & $185.7 \pm 137.2$ & $178.2 \pm 132.5$ & 0.298 \\
Leukocyte (K/uL) & $13700 \pm 7980$ & $14100 \pm 8860$ & 0.763 \\
Neutrophil (K/uL) & $12200 \pm 7670$ & $11900 \pm 8430$ & 0.841 \\
Platelet (K/uL) & $201400 \pm 102700$ & $242250 \pm 145200$ & 0.051 \\
Mean Platelet Volume (fl) & $8,0[7,0-9,0]$ & $7,0[7,0-9,0]$ & 0.114 \\
Platelet Distribution Width (\%) & $18,0[17,0-19,0]$ & $18,0[17,0-18,0]$ & $\mathbf{0 . 0 0 1}$ \\
\hline
\end{tabular}

Data were shown as mean \pm standard deviation, median $[\mathrm{IQR}]$ and $\mathrm{n}(\%)$.

Table 5: Results of ROC analysis for various biomarkers in predicting sepsis compared to control

\begin{tabular}{|c|c|c|c|c|c|c|c|}
\hline & $\begin{array}{l}\text { Cut-off } \\
\text { point }\end{array}$ & Sensitivity & Specificity & $\begin{array}{l}\text { Positive } \\
\text { Predictiv }\end{array}$ & $\begin{array}{l}\text { Negative } \\
\text { e Predictive }\end{array}$ & $\begin{array}{l}\text { AUC } \\
\text { of }\end{array}$ & $\begin{array}{l}\text { CI 95\% } \\
\text { AUC }\end{array}$ \\
\hline & & & & Value & Value & & \\
\hline Platelet $(K / u L)$ & $<=155$ & 35.86 & 95.80 & 89.7 & 59.6 & 0.599 & $\begin{array}{c}0.540- \\
0.656\end{array}$ \\
\hline Mean Platelet Volume (fl) & $>8$ & 53.47 & 87.41 & 81.1 & 65.1 & 0.752 & $\begin{array}{r}0.698- \\
0.801\end{array}$ \\
\hline Plateletdistribution Width & (o) $>17.9$ & 59.31 & 76.22 & 71.7 & 64.9 & 0.733 & $\begin{array}{r}0.678- \\
0.783 \\
\end{array}$ \\
\hline
\end{tabular}


Table 6: A multivariate logistic regression model of biomarkers and other covariates associated with sepsis

\begin{tabular}{lcccccr}
\hline Independent variables & $\hat{\mathbf{a}}$ & $\mathbf{S E}$ of $\hat{\mathbf{a}}$ & $\mathbf{p}$ & $\mathbf{O R}$ & \multicolumn{2}{c}{$\mathbf{9 5 \% \mathbf { C I } \text { for OR }}$} \\
\cline { 6 - 8 } & & & & & & \multicolumn{2}{c}{ Lower } & Upper \\
\hline Gender (Female) & $-0,206$ & 0,288 & 0,474 & 0,814 & 0,463 & 1,430 \\
Age (years) & $-0,019$ & 0,009 & 0,041 & 0,981 & 0,963 & 0,999 \\
Leukocyte $(K / u L)$ & 0,003 & 0,001 & 0,057 & 1,003 & 1,000 & 1,005 \\
Mean Platelet Volume $(f l)$ & 0,722 & 0,150 & $<0,001$ & 2,059 & 1,534 & 2,764 \\
Platelet Distribution Width (\%) 0,611 & 0,167 & $<0,001$ & 1,843 & 1,327 & 2,559 \\
\hline
\end{tabular}

â: Regression coefficient, SE: Standard error,OR: Odds Ratio, CI: confidence interval

\section{Discussion}

Our findings revealed that MPV and PDW were significant parameters in septic patients. These parameters were higher in septic patients than in controls. In addition, a lower platelet count was observed in septic patients. This situation was due to production of many cytokines, endothelial damage, and bone marrow suppression in septic patients.

Our findings indicated that greater MPV levels higher than $8 \mathrm{fl}$ have moderate $(53.47 \%)$ sensitivity and good $(87.41 \%)$ specificity for sepsis diagnosis. Therefore, MPV may be used as an auxiliary test in the diagnosis of sepsis. A high positive predictive value of this test $(81.1 \%)$ supports this hypothesis too. Moreover, in multivariate logistic regression analysis, the independent laboratory parameters in sepsis diagnosis were MPV [OR:2,05 (1,5 - 2,7)], and PDW [OR:1,8 (1,3-2,5)].

Patients with severe sepsis have lower platelet count, higher MPV, and increased PDW compared to patients with sepsis. On the other hand, leukocyte count, neutrophil count and CRP are not useful in a differential diagnosis of sepsis and severe sepsis. Therefore, platelet count and their indices can be used as a direct indicator of organ dysfunction.

Findings in a recent study support our results. In that study, low platelet count was found in the first three days of Gram-positive septic patients and in the first four days of Gram-negative sepsis. Similarly, MPV was found to be higher in the first three and five days of Gram-positive sepsis and Gram-negative sepsis, respectively. ${ }^{13}$ However, PDW was not reported in that study. In an animal-experiment study, researchers found that PDW was increased in the presence of endotoxemia. ${ }^{14}$ In a study conducted in newborns, Patrick et al reported that high levels of MPV and PDW have $95 \%$ and $79 \%$ specificity in the detection of bacteremia, respectively. ${ }^{15}$
The present study conducted in adults demonstrated that PDW was higher in sepsis patients, as were MPV levels. Moreover, PDW and MPV levels in severe sepsis patients were higher than in patients with sepsis. It has been demonstrated that coagulation and platelet activation/hyper aggregation can occur in an early phase of sepsis. ${ }^{3}$ In order to obtain a larger surface, platelets change their discoid shape to a spherical shape during activation. At the same time, pseudopodia formation occurs. Platelets with increased number and size of pseudopodia may affect the PDW..$^{16}$ Platelet volume is related to platelet function and activation as well. Generally, platelet production increases as platelet count decreases. An increased number of young platelets is also functionally more active than older platelets. ${ }^{17}$ The low level of thrombocytopenia in patients with severe sepsis can explain the high levels of MPV and PDW.

PDW was the only significant distinctive laboratory parameter different between survivors and non-survivors. The threshold of PDW in estimating death was $18 \%$. Septic patients who have greater than $18 \%$ PDW have a higher risk of death. In a study that examined 13,701 healthy adults in the United States, among the platelet indices, only PDW, and not platelet count or MPV was found to be an independent predictor of all-cause and cardiovascular mortality. ${ }^{18}$ Hence PDW can be used as a parameter in estimating death rate among septic patients.

\section{Conclusion}

MPV and PDW are significant parameters in the diagnosis of sepsis and in the differential diagnosis of sepsis and severe sepsis. PDW is an important parameter for estimating the death rate among septic patients. MPV and PDW values in whole blood counts, which is performed for almost all patients 
admitted to health facilities, should be carefully monitored in patients with sepsis.

\section{Acknowledgements}

We would like to extend our thanks to Assistant Prof.

Dr. Unal Erkorkmaz for his help in statistical analysis.

\section{References}

1. Dellinger RP, Levy MM, Carlet JM, et al. Surviving Sepsis Campaign: international guidelines for management of severe sepsis and septic shock: 2008. Crit Care Med. 2008;36(1):296 -327.

2. Ventetuolo CE, Levy MM. Sepsis: a clinical update. Clin J Am Soc Nephrol. 2008;3(2):571-7.

3. Becchi C, Al Malyan M, Fabbri LP, Marsili M, Boddi V, Boncinelli S. Mean platelet volume trend in sepsis: is it a useful parameter? Minerva Anestesiol. 2006;72(9):749-56.

4. Warkentin TE, Aird WC, Rand JH. Plateletendothelial interactions: sepsis, HIT, and antiphospholipid syndrome. Hematology Am Soc Hematol Educ Program. 2003:497-519.

5. Acikgoz S, Akduman D, Eskici Z.M, et al. Thrombocyte and erythrocyte ýndýces ýn sepsýs and dýssemýnated ýntravascular coagulatýon. $J$ Med Biochem 2012; 31:60-64

6. Lee KH, Hui KP, Tan WC. Thrombocytopenia in sepsis: a predictor of mortality in the intensive care unit. Singapore Med J. 1993;34(3):245 -6.

7. Munford RS, Suffredini AF. Sepsis, Severe sepsis, and septic shock. In Mandell GL, Bennett JE, Dolin R. (Eds.) Mandell, Douglas, and Bennett's Principles and Practice of Infectious Diseases. Seventh Edition. Philadelphia: Churchill Livingstone; 2010. p:987-1010

8. Daly ME. Determinants of platelet count in humans. Haematol. 2011;96:10-13 .

9. Chapter 133/Platelet Disorders. The Merck Manual of Diagnosis and Therapy. Beers MH,
Berkow R. (Eds.) Seventeenth Edition. Merck and Co.,Inc. U.S.A. 1999; p:920-928.

10. Littleton N. Thrombocytopenia in HIV. CME. 2007;25:272-275

11. Nugent D, McMillan R, Nichol JL,Slichter SJ. Pathogenesis of chronic immune thrombocytopenia: increased platelet destruction and/or decreased platelet production. Br J Haematol. 2009;146:585-96

12. Farias MG, Schunck EG, Dal Bo S, de Castro SM. Definition of reference ranges for the platelet distribution width (PDW): a local need. Clin Chem Lab Med. 2010;48:255-7

13. Aydemir H, Piskin N, Akduman D, Kokturk F, Aktas E. Platelet and mean platelet volume kinetics in adult patients with sepsis. Platelets. 2012 Jun 25. (Epub ahead of print)

14. Yýlmaz Z, Eralp O, Ilcol YO. Evaluation of platelet count and its association with plateletcrit, mean platelet volume, and platelet size distribution width in a canine model of endotoxemia. Vet Clin Pathol. 2008;37:15963 PubMed

15. Patrick CH, Lazarchick J. The effect of bacteremia on automated platelet measurements in neonates. Am J Clin Pathol. 1990;93:391-4

16. Vagdatli E, Gounari E, Lazaridou E, Katsibourlia E, Tsikopoulou F, Labrianou I. Platelet distribution width: a simple, practical and specific marker of activation of coagulation. Hippokratia. 2010;14:2832 PubMed .

17. Bilici S, Sekmenli T, Göksu M, Melek M, Avci $\mathrm{V}$. Mean platelet volume in diagnosis of acute appendicitis in children. Afr Health Sci. 2011;11:427-432

18. Qayyum R, Vaidya D. Platelet Distribution Width is an independentpredictor of all-cause and cardiovascular mortality among healthy US adults. Circulation. 2011;124:A1678 